\title{
CHOOSING A BUYING OPTION FOR DIABETES MEDICAL DEVICES USING THE SUPERDECISIONS SOFTWARE
}

\author{
Martha Merrill \\ University of Pittsburgh \\ Pittsburgh, PA, USA \\ E-mail: mvb12@pitt.edu
}

\begin{abstract}
Diabetes is considered one of the world's most burdensome diseases. A medical device, which eliminates the effects of diabetes, would save numerous lives and significantly reduce costs to healthcare systems around the world. Inventors in bioengineering and medicine are developing technology to reduce the effects of diabetes. If these medical devices are found promising, then their inventors might approach large device companies to help manufacture and distribute. This model simulates the situation in which an inventor of a promising medical device in phase III of clinical trials approaches the board of directors of a device company (BioMed, BM). BM hopes to change their status from competitor to market leader. The Benefits, Opportunities, Costs, and Risks (BOCR) model as detailed by Saaty and Peniwati is used to determine whether acquisition, licensing, or passing on the offer is in the best interest of the company. Using additive and multiplicative models, acquisition and licensing are found as the best courses of action, respectively. After completion of the model, the author suggests that BM licenses the device with the option to buy when the product passes all clinical trials and obtains FDA approval. This model can be improved by a specific scenario and further development by experts in the field.
\end{abstract}

Keywords: diabetes, medical devices, acquisition, SuperDecisions, AHP. 


\section{Introduction}

Diabetes is one of the world's most burdensome diseases. Of the trillions of dollars spent on healthcare in the world, $11 \%$ goes to diabetes. Currently, 25.8 million people live with the disease in the United States and \$245 billion USD was spent in 2012, a 41\% increase from 2007. These numbers are expected to increase even more in the next 15 years. Globally, as many as 371 million people live with the disease. These values do not include the millions of dollars spent on complications of diabetes, including heart disease, stroke, hypertension, and more. Diabetes is a progressive disease, which means patients' diabetes will worsen over time no matter the course of medical treatment. All products currently available aim to delay the progression of diabetes, but do not eliminate it.

Change in lifestyle, oral agents, injectables, and insulin pumps are the current products on the market to delay the progression of diabetes. With all of these forms, however, the patient will still develop serious cardiovascular and kidney complications, such as heart attack, stroke, and chronic kidney disease. Currently, medical devices with the potential to reduce or eliminate the effects of diabetes are nearing the end of clinical trials. Within the next 3-5 years, these devices could gain FDA approval, and enter the health market.

\section{Literature Review}

Since this study is meant to pilot future decisions about acquisition of medical devices, the most beneficial literature background is the textbook by Saaty and Peniwati. This book gives the basis for the decision framework and would be helpful for those looking to repeat the process with different market situations, i.e. a specific company and a specific medical device. Similarly, the current state of medical devices is based on a Congressional Report done on "FDA Regulation of Medical Devices" by Judith Johnson at the end of 2011. Much information about the burden of diabetes on domestic and international healthcare systems can be found on the websites of the Centers for Disease Control and Prevention, the International Diabetes Federation, and the American Diabetes Association.

\section{Hypotheses/Objectives}

As stated in the introduction, health systems could see medical devices attempting to eliminate the effects of diabetes enter the market in the next five years. Since the likelihood of multiple devices passing clinical trials and tackling the regulation hurdles is low, this study assumes one medical device successfully enters the market and is called the Diabetes Medical Device (DMD). For the sake of the SuperDecisions pilot decision, the DMD is defined as an advanced medical device, which eliminates the effects of diabetes when installed. The device is implanted into the user, and following installation the user no longer needs to test for glucose or be mindful of their sugar intake. According to early clinical trials, the device remains in the body for 10 years with $20 \%$ of the population needing a replacement in 3-5 years.

The managerial problem is from the perspective of a major medical device manufacturer, called BioMed (BM). BM produces a number of medical devices, including pacemakers, stents, and glucose meters. The inventor of the DMD has approached BM as phase III clinical trials are conducted. The inventor is interested in selling or licensing his invention to BM. Should the board of directors at BM acquire or license the innovative medical device? Alternatively, they can pass on the offer, and another medical device 
company might strike a deal with the inventor. Currently a competitor and not a market leader, BM hopes to become a market leader and wonders if the high confidence of the inventor is enough for them to take on the risk.

Since BM wishes to become a market leader and this device has the potential to be disruptive technology in the field, the author hypothesizes that acquiring the device by $\mathrm{BM}$ would be the most beneficial outcome for BM. With the hypothesis in mind, this model creates a quantitative framework for why the company would acquire the DMD over licensing with the inventor or passing on the offer.

\section{Research Design/Methodology}

The model was created using the concepts of strategic criteria with the BOCR analysis as outlined in the Saaty and Peniwati book (Figure 1). The author created the model and conducted the pairwise comparisons based on discussions with other graduate students in the fields of Pharmacy and Public Health about the future of diabetes medical devices.
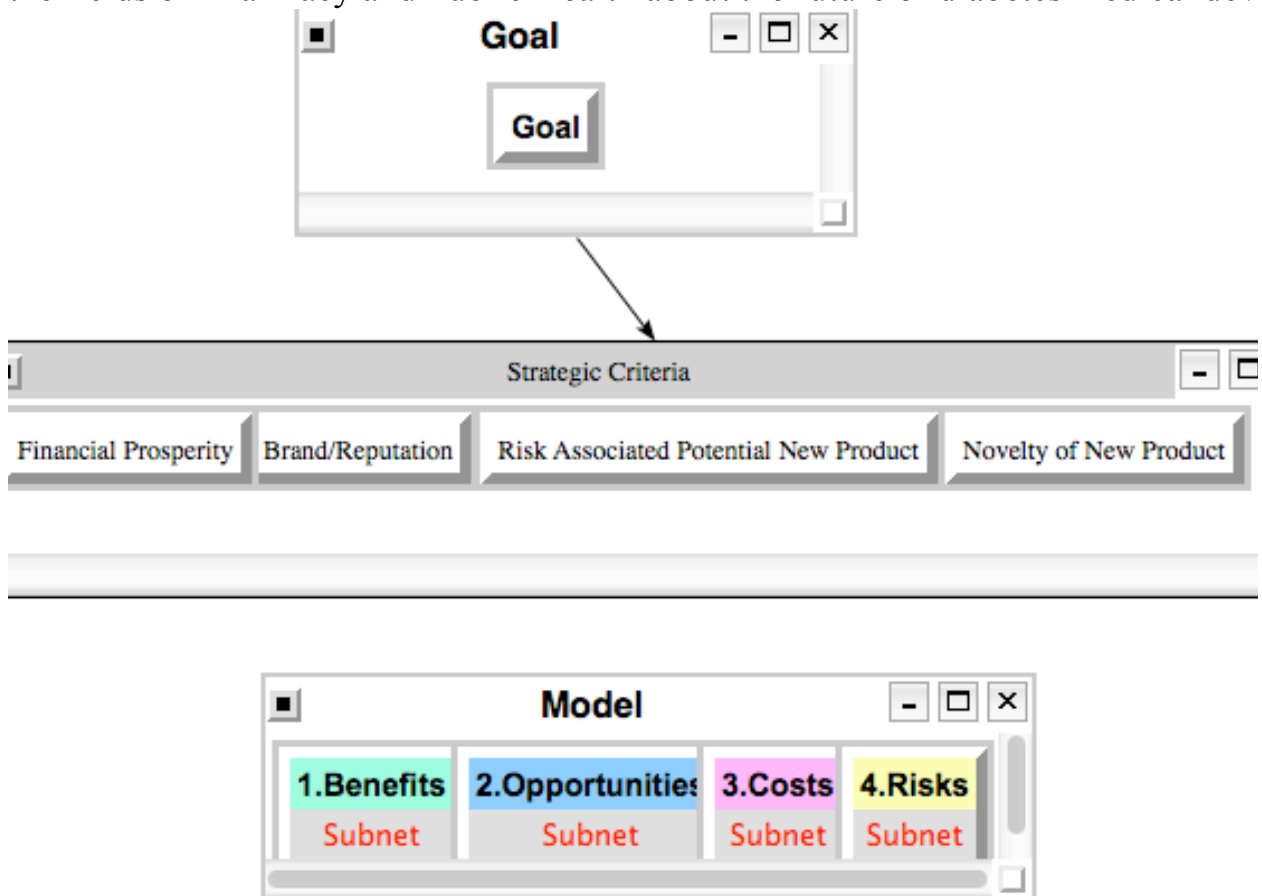

Figure 1. Complete BOCR model for the decision on the DMD elimination device.

In creating this model, the potential effects of the decision made by the board of directors at BM were considered, and an attempt was made to include all consequences. Additional information about a specific product and a specific company would produce a more accurate model. Since the goal of the project is to make a general decision tree that could be used by many companies, the model uses generalities and trends in the medical device market as a whole. Additionally, experts in the field, rather than only graduate students, would certainly add value in the construction of the model. The author's perspective as a bioengineering student most likely has colored and influenced the choices made in the model making process. 
ISAHP Article: Merrill/Choosing a Buying Option for Diabetes Medical Devices Using the SuperDecisions Software, Washington D.C., U.S.A.

\section{Data/Model Analysis}

The results were obtained by synthesizing the whole model in the SuperDecisions software. First, the additive (negative) formula was used (bB+oO-cC-rR). The data from the subnets of Benefits, Opportunities, Costs, and Risks are displayed in Figures 2-5. Interestingly, "Acquire device" has the highest ranking for Benefits, Opportunities, and Costs (Figure 6). "No offer" is the riskiest of the options. When the additive (negative) formula is used with these results, "Acquire device" is found to be the best option for the board of directors of BM in the long term. Close behind is "License device," which has a similar priority value as "Acquire device."

Next, the multiplicative formula for BOCR synthesis was performed. This formula multiplies Benefits and Opportunities and then divides by the product of Costs and Risks $(\mathrm{BO} / \mathrm{CR})$. The results of this formula are found in Figure 7. In this case, "License device" is found to be the best course of action for the board of directors in the short term.

\begin{tabular}{||c|c|c|c|c|c|c|}
\hline Graphic & Alternatives & Total & Normal & Ideal & Ranking \\
\hline \hline & Acquire device & 0.9468 & 0.4314 & 1.0000 & 1 \\
\hline \hline & License device & 0.7712 & 0.3514 & 0.8145 & 2 \\
\hline \hline & No offer & 0.4767 & 0.2172 & 0.5035 & 3 \\
\hline \hline
\end{tabular}

Figure 2. Results from Benefits subnet.

\begin{tabular}{||c||c||c|c|c|c|}
\hline Graphic & Alternatives & Total & Normal & Ideal & Ranking \\
\hline \hline & Acquire device & 0.9335 & 0.4507 & 1.0000 & 1 \\
\hline \hline & License device & 0.7342 & 0.3545 & 0.7865 & 2 \\
\hline \hline & No offer & 0.4036 & 0.1948 & 0.4323 & 3 \\
\hline \hline
\end{tabular}

Figure 3. Results from Opportunities subnet.

\begin{tabular}{||c||c|c|c|c|c|c|}
\hline Graphic & Alternatives & Total & Normal & Ideal & Ranking \\
\hline \hline & Acquire device & 0.9080 & 0.5077 & 1.0000 & 1 \\
\hline \hline & License device & 0.5624 & 0.3145 & 0.6194 & 2 \\
\hline \hline & No offer & 0.3179 & 0.1778 & 0.3501 & 3 \\
\hline \hline
\end{tabular}

Figure 4. Results from Costs subnet.

\begin{tabular}{||c|c|c|c|c|c|c|}
\hline Graphic & Alternatives & Total & Normal & Ideal & Ranking \\
\hline \hline & Acquire device & 0.8386 & 0.3419 & 0.9076 & 2 \\
\hline \hline & License device & 0.6904 & 0.2815 & 0.7472 & 3 \\
\hline \hline & No offer & 0.9240 & 0.3767 & 1.0000 & 1 \\
\hline \hline
\end{tabular}

Figure 5. Results from Risks subnet.

\begin{tabular}{|l|l|c|c|c|c|}
\hline \multicolumn{1}{|c|}{ Name } & \multirow{2}{*}{ Graphic } & Ideals & Normals & Raw \\
\hline Acquire device & & 1.000000 & 0.401822 & 0.265939 \\
\hline \hline License device & & 0.992910 & 0.398973 & 0.264053 \\
\hline \hline No offer & & 0.495753 & 0.199204 & 0.131840 \\
\hline
\end{tabular}

Figure 6. - Results of synthesis using the Additive (negative) Formula. 
ISAHP Article: Merrill/Choosing a Buying Option for Diabetes Medical Devices Using the SuperDecisions Software, Washington D.C., U.S.A.

\begin{tabular}{|c|c|c|c|c|}
\hline \hline \multicolumn{1}{|c|}{ Name } & Graphic & Ideals & Normals & Raw \\
\hline \hline Acquire device & & 0.796039 & 0.354558 & 1.160704 \\
\hline \hline License device & & 1.000000 & 0.445403 & 1.458099 \\
\hline \hline No offer & & 0.449119 & 0.200039 & 0.654860 \\
\hline
\end{tabular}

Figure 7. - Results of synthesis using the Multiplicative Formula.

\section{Limitations}

Improvements can most widely be made in the Risks subnet. Many of the risks were difficult to gauge accurately with a general scenario, and the pairwise comparisons would be more complete with more information and with the help of someone expert in patent litigation. Both licensing and acquisition had a high level of risk associated with patent litigation, but this risk could be mitigated with the appropriate legal expertise. This change would make both licensing and acquisition less risky and more favorable as courses of action. The effect would mostly be on acquisition, however, since in licensing, the burden was assumed to fall on both the inventor and the company.

In general, the whole model could be improved with a specific product and a specific company. Then, the effects would not be estimated. The current model, however, is still beneficial to a company who needs to make a decision about a medical device.

\section{Conclusions}

The SuperDecisions software helped find that acquiring the DMD is in the best interest of the board of directors in the long term. However, licensing the device had a similar priority (very close) and was found to be beneficial in the short term. Based on these data, the board of directors should license with option to buy with successful attainment of FDA approval. This decision mitigates the risk of the product not completing clinical trials nor passing FDA regulation. The inventor also has higher stake in the success of the product, both monetarily and through his continued work with the company. With FDA approval, BM should offer the inventor a lump sum of money for the product. This sum can be calculated using a Bass adoption model and financial projections of the product over its lifetime.

The largest risk with the suggested course of action is that another company could offer a better deal for acquisition or licensing, and the inventor accepts another company's offer. Thus, more information about the companies involved would be necessary to create a SuperDecisions model to predict the best route for the inventor. A model based on the inventor's choices could further help BM make its decision. If the company brand is not desirable to the inventor and a "no" is probable, then the board of directors could increase the price for the DMD or invest in another product.

\section{Key References}

Saaty, T.L., \& Peniwati, K. (2007). Group decision-making: Drawing out and reconciling differences. Pittsburgh, PA: RWS Publications.

Library of Congress. Congressional Research Service. American Law Division. (2011). FDA regulation of medical devices 